\title{
Dendrimer-based Nanoparticle for Dye Sensitized Solar Cells with Improved Efficiency
}

William Ghann ${ }^{1}$, Hyeonggon Kang ${ }^{1}$, Jamal Uddin ${ }^{1 *}$, Sunalee J Gonawala ${ }^{2}$, Sheikh Mahatabuddin² and Meser M Ali*

${ }^{1}$ Department of Natural Sciences, Center for Nanotechnology, Coppin State University, Baltimore, MD21216, USA

${ }^{2}$ Department of Neurosurgery, Cellular and Molecular Imaging Laboratory, Henry Ford Hospital, Detroit, MI, USA

\begin{abstract}
Dye sensitized solar cells were fabricated with DyLight680 (DL680) dye and its corresponding europium conjugated dendrimer, DL680-Eu-G5PAMAM, to study the effect of europium on the current and voltage characteristics of the DL680 dye sensitized solar cell. The dye samples were characterized by using Absorption Spectroscopy, Emission Spectroscopy, Fluorescence lifetime and Fourier Transform Infrared measurements. Transmission electron microscopy imaging was carried out on the DL680-Eu-G5PAMAM dye and DL680-Eu-G5PAMAM dye sensitized titanium dioxide nanoparticles to analyze the size of the dye molecules and examine the interaction of the dye with titanium dioxide nanoparticles. The DL680-Eu-G5PAMAM dye sensitized solar cells demonstrated an enhanced solar-to-electric energy conversion of $0.32 \%$ under full light illumination (100 $\mathrm{mWcm}^{-2}$, AM $\left.1.5 \mathrm{Global}\right)$ in comparison with that of DL680 dye sensitized cells which recorded an average solar-to-electric energy conversion of only $0.19 \%$. The improvement of the efficiency could be due to the presence of the europium that enhances the propensity of dye to absorb sunlight.
\end{abstract}

Keywords: Nanoparticle; Solar cells; Dendrimer; Dye

\section{Introduction}

Dye sensitized solar cells (DSSCs) are a promising renewable form of energy that are easy to fabricate, portable, low cost, environmentally friendly and have a relatively high solar-to-electric energy conversion efficiency [1-5]. Dye sensitzed solar cells were invented by Michael Gratzel et al. in 1991 and has since generated a lot of interest leading to an exponential growth in reseach relating to DSSC [6,7]. It is generally composed of two conductive glass electrode, a photoande and a counter electrode, with a redox electrolyte sandwiched between them. The electrolyte ensures the regeneration of charge. Much of the work in the field has centered on the manipulation and enhancement of the afformentioned components and the resulting effect on the production of highly efficient solar cells [8-11]. The photoanode comprises of a dye sensitized titanium dioxide nanoparticle film on a fluorinedoped tin oxide (FTO) transparent glass. The dye adsorbed on the titanium dioxide semiconductor, absorbs radiant energy and generate charges which travel through the semiconductor to the conductive layer and subsequently through an external ciruit to the cathode. The electrolyte commonly used in the fabrication of dye sensitized solar cell is Iodine/triodine redox couple system. Other electrolyte have been developed which have also been found to enhance the efficiency of solar cells $[12,13]$. However, the most critical component of the device is the sensitizing dye that is utilized in the construction of the solar cell. The dye is expected to show a high absorption in the UVvisible and infrared region. The dye must also have anchoring groups, usually carboxylic groups capable of attaching to the surface of the titanium dioxide nanoparticles [14]. A number of different dyes have been explored in the production of dye sensitized solar cells [1517]. DyLight 680 (DL680) is a near infrared fluorescent dye that is frequently used in bioanalysis and bioimaging. It is often conjugated to other imaging probes to afford multimodal imaging. DL680 conjugated with europium has been successfully employed for MRI and fluorescene imaging [18-20]. This dye has the potential for use as sensitizing dye in dye sensitized solar cells due to the presence of large number of surface carboxylic groups capable of binding to the titanium dioxide semiconducter, consequently enhancing the transport of charge. In this study, DL680 conjugated to an europium incorporated generation 5 poly(amidoamine) (G5PAMAM) denderimer (DL680-
Eu-G5PAMAM) was deployed as a sensitizing dye for the fabrication of solar cells in order to compare its perfomance witht that of bare DL680 dye sensitized solar cells.

\section{Experimental Section}

\section{Materials}

Titanium dioxide powder (Degussa P25) was purchased from the institute of chemical education. Fluorine tin oxide (FTO) conducting glass slides were purchased from Harford glass company, Hartford City, Indiana. Sodium Hydroxide $(\mathrm{NaOH})$, acetone $\left(\mathrm{C}_{3} \mathrm{H}_{6} \mathrm{O}\right)$, ethanol $\left(\mathrm{C}_{2} \mathrm{H}_{5} \mathrm{OH}\right)$, and acetic acid $\left(\mathrm{CH}_{3} \mathrm{COOH}\right)$ were purchased from SigmaAldrich and were used without further purification. Graphite used in making cathode slides was purchased from TED PELLA, INC.

The photoanode was prepared on a fluorine-doped $\mathrm{SnO}_{2}$ (FTO) conducting glass substrate. The FTO glass slides were cleaned with detergent solution, rinsed first with water, and then with ethanol. The FTO glass substrates were subsequently spin coated with $\mathrm{TiO}_{2}$ paste prepared from $\mathrm{TiO}_{2}$ powder, acetic acid, and soap water. The $\mathrm{TiO}$ coated FTO slides were annealed at $450^{\circ} \mathrm{C}$ for an hour and allowed to cool to room temperature. Using Field Emission Scanning Electron Microscopy cross-sectional imaging, the thickness of the $\mathrm{TiO}_{2}$ layer was determined to be approximately $8 \mu \mathrm{m}$. To prepare the cathode, graphite paint was spread uniformly on the cleaned FTO glass and allowed to dry at room temperature.

*Corresponding authors: Jamal Uddin, Department of Natural Sciences, Center for Nanotechnology, Coppin State University, Baltimore, MD21216, USA, Tel: 1-4109514118; Fax: 14109514110; E-mail: juddin@coppin.edu

Meser M Ali, Department of Neurosurgery, Cellular and Molecular Imaging laboratory, Henry Ford Hospital, Detroit, MI, USA, Tel: 1-3138744479; Fax: 13138744494; E-mail: mali8@hfhs.org

Received: April 04, 2018; Accepted: April 10, 2018; Published: April 13, 2018

Citation: Ghann W, Kang H, Uddin J, Gonawala SJ, Mahatabuddin S, et al. (2018) Dendrimer-based Nanoparticle for Dye Sensitized Solar Cells with Improved Efficiency. J Nanomed Nanotechnol 9: 496. doi: 10.4172/2157-7439.1000496

Copyright: $\odot 2018$ Ghann W, et al. This is an open-access article distributed under the terms of the Creative Commons Attribution License, which permits unrestricted use, distribution, and reproduction in any medium, provided the original author and source are credited. 
Citation: Ghann W, Kang H, Uddin J, Gonawala SJ, Mahatabuddin S, et al. (2018) Dendrimer-based Nanoparticle for Dye Sensitized Solar Cells with Improved Efficiency. J Nanomed Nanotechnol 9: 496. doi: 10.4172/2157-7439.1000496

Page 2 of 6

\section{Synthesis of DL680-Eu-G5PAMAM}

The synthesis of DL680-Eu-G5PAMAM was conducted by following the method described in our previous report [18]. Briefly, Eu-DOTA-Gly4 was synthesized first [18], and then was coupled with NHS and 1-ethyl-3-(3-dimethylaminopropyl) carbodiimide. $\mathrm{HCl}$ in 2-(N-morpholino)ethanesulfonic acid buffer. The resulting active ester, Eu-DOTA-Gly4-NHS, was added in aliquots of a G5 PAMAM dendrimer and then allowed to stir at room temperature for $24 \mathrm{~h}$. The solution was filtered using a centrifugal filter unit with a 10,000-molecular weight cut-off (Millipore Inc., MA, USA). Finally, the solution was lyophilized to obtain [Eu-DOTA-Gly4]42-G5PAMAM] as white solid. Then, a solution of DL680-NHS ester (50 mg, $\sim 0.071$ mmol; Thermo Fisher Scientific, IL, USA) in dimethyl sulfoxide was added to a stirred solution of Eu-G5PAMAM $(200 \mathrm{mg}, 0.071 \mathrm{mmol})$ in $2 \mathrm{ml}$ of PBS, and the reaction was stirred at room temperature for $24 \mathrm{~h}$. The reaction mixture was diafiltrated using Amicon Ultra centrifugal filter unit with a 10,000-molecular weight cut-off. The solution was lyophilized to obtain $210 \mathrm{mg}$ of solid ( 066 mmol, 93\% yield).

\section{Fluorescence lifetime measurements}

DL680-Eu-G5PAMAM conjugate and DL680 dye were each dissolved in $3 \mathrm{~mL}$ of ethanol for fluorescence lifetime measurements. To prevent inner filter effect, absorption measurements were first carried out to ensure the absorbance of the dyes was less or equal to 0.15 a.u. Fluorescence decays were measured using Horiba Deltaflex fluorescence lifetime system using the time-correlated single-photon counting (TCSPC) technique with the PPD-850 picosecond photon detection module. The excitation source was $532 \mathrm{~nm}$ light-emitting diodes (Delta LED) with $532 \mathrm{~nm}$.

\section{Fabrication of solar cell}

The DSSCs were prepared according to previously published protocols [21-23]. The $\mathrm{TiO}_{2}$ coated FTO glass was immersed in freshly prepared solutions of DL680-Eu-G5PAMAM and DL680 for a period of two hours. The counter electrode (cathode) was prepared by painting colloidal graphite on FTO glass substrate. Each of DL680-EuG5PAMAM nanoparticles and DL680 dye-sensitized electrodes and their respective counter electrode were assembled to form solar cells sandwiched with a redox $\left(\mathrm{I}^{-} / \mathrm{I}^{3-}\right)$ electrolyte solution.

\section{Characterization techniques}

Steady-state absorption spectra of DL680-Eu-G5PAMAM and DL680 dye solutions were acquired using UV-3600 Plus from Shimadzu. Steady-state fluorescence spectra were recorded on the fluorescence Nanolog Spectrofluorometer System from Horiba Scientific (FL3-22 iHR, Nanolog). ATR spectra was obtained with a Thermo Nicolet iS50 FTIR. The morphology of each film was analyzed using field emission scanning electron microscopy (FESEM; JSM-7100FA JEOL USA, Inc.). Transmission Electron Microscopy (TEM) images were acquired on JEM-1400 Plus (JEOL USA, Peabody, Massachusetts). The images were viewed using Digital Micrograph software from Gatan (Gatan, Inc, Pleasanton, CA). $\mathrm{TiO}_{2}$ paste was printed on FTO glass using WS-650 Series Spin Processor from Laurell Technologies Corporation.

\section{Photovoltaic properties measurement}

The energy efficiencies of the fabricated DL680-Eu-G5PAMAM and DL680 DSSCs were measured using $150 \mathrm{~W}$ fully reflective solar simulator with a standard illumination with air-mass 1.5 global filter (AM $1.5 \mathrm{G}$ ) having an irradiance corresponding to 1 sun $(100 \mathrm{~mW} /$ $\mathrm{cm}^{2}$ ) purchased from Sciencetech Inc., London, Ontario, Canada and Reference 600 Potentiostat/Galvanostat/ZRA from Gamry Instruments (734 Louis Drive, Warminster, PA 18974). The tested solar cells were masked to an area of $5 \mathrm{~cm}^{2}$. Each cell performance value was taken as the average of three independent samples. The solar energy to electricity conversion efficiency $(\eta)$ was calculated based on the equation, $\eta=F F \times I s c \times V o c$, where FF is the fill factor, Isc is the shortcircuit photocurrent density $\left(\mathrm{mA} \mathrm{cm}^{-2}\right)$, and $\mathrm{Voc}$ is the open-circuit voltage $(\mathrm{V})$ as listed in Table 1.

\section{Results and Discussion}

The synthesis of DL680-Eu-G5PAMAM was carried out according to a previously published method [18]. The europium compound was first synthesized and subsequently conjugated to the generation five PAMAM dendrimer via the amino groups on the surface of the dendrimer. The DL680 molecules were also conjugated on the amines surface of the dendrimer as displayed in Figure 1.

\section{UV-Vis absorption studies}

The absorption characteristics of the DL680 and DL680-EuG5PAMAM dyes were studied via UV-Visible measurements. Absorption spectra of DL680 and DL680-Eu-G5PAMAM as displayed in Figure 2 show a wavelength of maximum absorption of DL680 to be $677 \mathrm{~nm}$ and that of DL680-Eu-G5PAMAM to be $690 \mathrm{~nm}$. Therefore,

\begin{tabular}{|c|c|c|c|c|c|c|}
\hline DSSC & $\mathbf{V}_{\max }$ & $\mathbf{I}_{\max }$ & $\mathbf{V}_{\text {oc }}$ & $\mathbf{I}_{\text {sc }}$ IA & FF & $\begin{array}{c}\text { Efficiency } \\
\text { (\%) }\end{array}$ \\
\hline $\begin{array}{c}\text { DL680-Eu- } \\
\text { G5PAMAM }\end{array}$ & 0.28 & 1.13 & 0.46 & 1.66 & 0.42 & 0.32 \\
\hline DL680 & 0.19 & 1.01 & 0.35 & 1.84 & 0.30 & 0.19 \\
\hline
\end{tabular}

Table 1: Current voltage characteristics of DL680-Eu-G5PAMAM and DL680 dye sensitized solar cells.

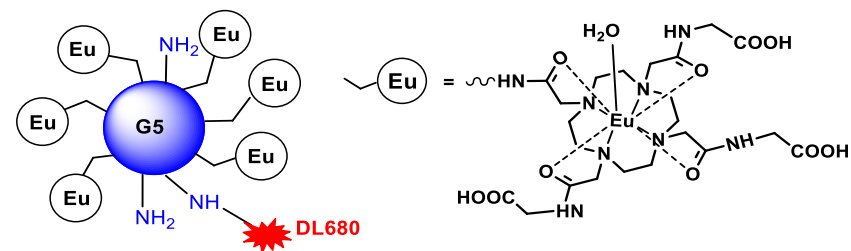

Figure 1: Schematic view of (Eu-DOTA-Gly4)42-G5-DL680). Eu-DOTA-Gly4 and DyLight680 (DL680) were conjugated on the amines surface of a G5 PAMAM dendrimer.

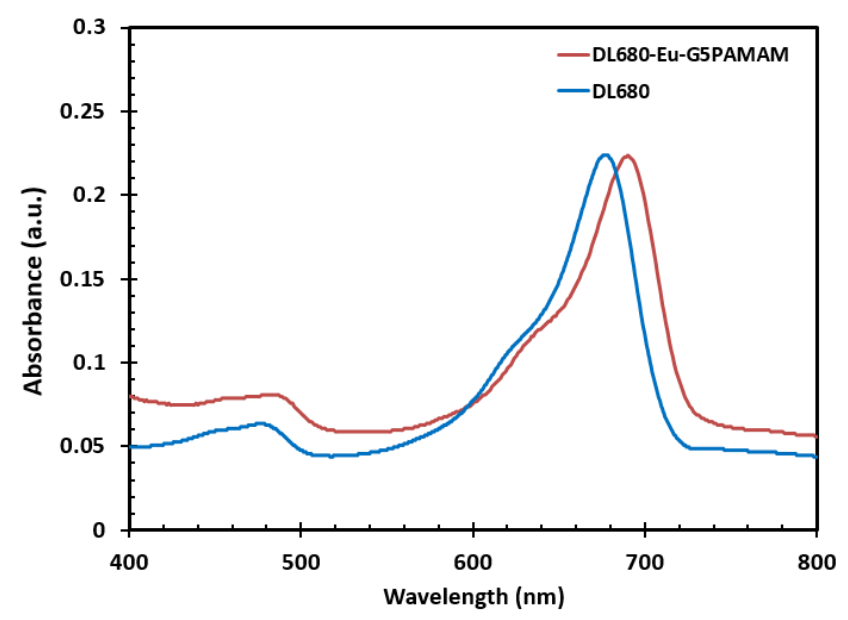

Figure 2: Absorption spectra of aqueous solutions of DL680 and DL680-EuG5PAMAM dyes. 
Citation: Ghann W, Kang H, Uddin J, Gonawala SJ, Mahatabuddin S, et al. (2018) Dendrimer-based Nanoparticle for Dye Sensitized Solar Cells with Improved Efficiency. J Nanomed Nanotechnol 9: 496. doi: 10.4172/2157-7439.1000496

Page 3 of 6

conjugation DL680 with Eu-G5PAMAM resulted a red shift from $677 \mathrm{~nm}$ to $690 \mathrm{~nm}$. This is an indication of the successful conjugation of the DL680 dye to the europium complex. In addition to the main absorption band that extends to the near infrared region, there is another band which appears at $485 \mathrm{~nm}$. Thus, absorption encompasses most of the visible spectral range and enters the near-infrared region. It is also observed that the light absorption of DL680-Eu-G5PAMAM in the visible region is stronger than that of DL680 which suggest that it would be a better sensitizing agent.

\section{Steady state fluorescence studies}

The steady state fluorescence spectra of DL680 and DL680-EuG5PAMAM were taken as part of the photophysical studies on the dyes and are shown in Figure 3. The measurements were carried out in water with an exciting light of $600 \mathrm{~nm}$. The emission maximum of DL680Eu-G5PAMAM at $709 \mathrm{~nm}$ is redshifted with respect to DL680 which exhibited an emission maximum at $698 \mathrm{~nm}$.

\section{IR spectroscopy analysis}

The Fourier transformed infrared spectra of the DL680 and DL680-Eu-G5PAMAM were also collected as part of the study on the photophysical properties of the dyes. The FTIR spectra of the dyes as displayed in Figure 4 verify that the DL680 dye was successfully

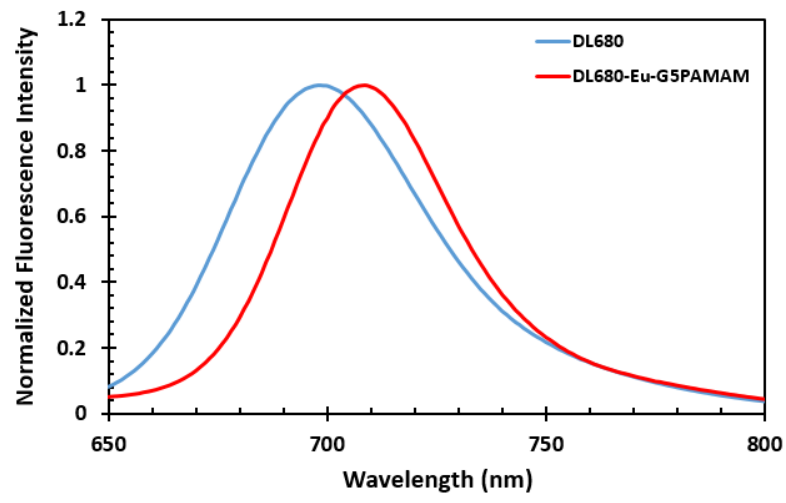

Figure 3: Emission spectra of DL680 and DL680-Eu-G5PAMAM in water

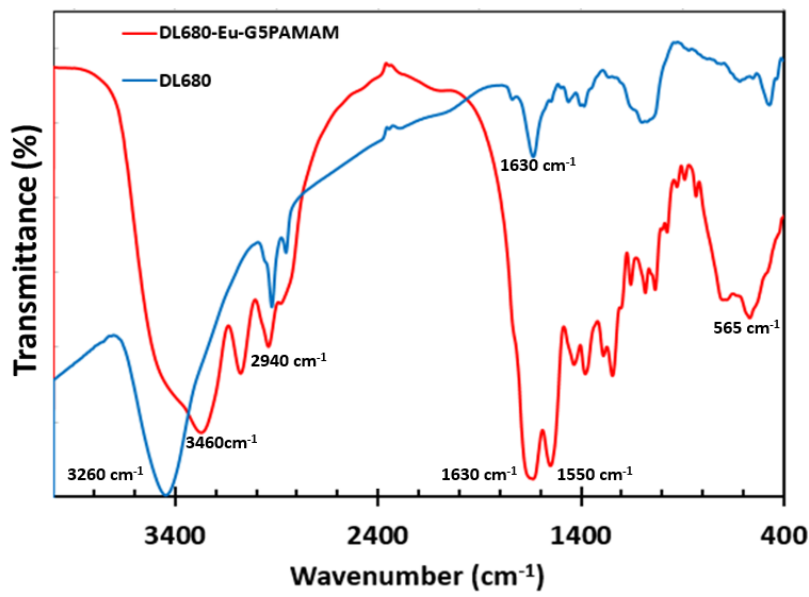

Figure 4: Fourier-transform infrared spectra of DL680 and DL680-EuG5PAMAM showing peaks of interest. conjugated to the Eu-G5PAMAM nanoparticle. As shown in prior studies, PAMAM dendrimer exhibits peaks at 3286 and $3345 \mathrm{~cm}^{-1}$ corresponding to the primary amino groups on the surface of the dendrimer [24,25]. These peaks, however, merge into a broad absorption peak upon conjugation as displayed in Figure 4. The characteristic absorption of the amide bonds also got red shifted to $1630 \mathrm{~cm}^{-1}$ and $1550 \mathrm{~cm}^{-1}$ as previously reported [24,25].

\section{Fluorescence lifetime studies}

Fluorescence lifetime (FLT) measurements (Figure 5) were carried out to study the period dye molecules reside in the excited state and how this lifetime influences the various parameters associated with DSSCs constructed with them. The lifetime of the dendritic dye was found to be $2.11 \mathrm{~ns}$ with a standard deviation of $0.0027 \mathrm{~ns}$ and that of only DL680 dye was $1.25 \mathrm{~ns}$ with a standard deviation of $0.0025 \mathrm{~ns}$ as displayed in Table 2. Luminescent europium complexes have been reported to exhibit long lifetime and are also highly stable in terms of ligand-metal dissociation and have widely been used as donors in Förster resonance energy transfers [26-28]. It is therefore reasonable that upon conjugation of the europium chelate to the DL680, the luminescence lifetime is significantly extended.

\section{Raman spectroscopy}

The DL680 and DL680-Eu-G5PAMAM were further characterized using Raman Spectroscopy. The Raman studies were performed in the range of $0-2000 \mathrm{~cm}^{-1}$ and the results are shown in Figure 6. There are three unique bands at $624 \mathrm{~cm}^{-1}, 806 \mathrm{~cm}^{-1}$ and $1070 \mathrm{~cm}^{-1}$ associated with both DL680 and G5EuDyl680. However, there are no corresponding bands of DL680-Eu-G5PAMAM to the peaks at $1630 \mathrm{~cm}^{-1}, 1430 \mathrm{~cm}^{-1}$ and $1290 \mathrm{~cm}^{-1}$ observed in the spectra of the DL680 dye. Instead a broad band that stretches $1750 \mathrm{~cm}^{-1}$ to $1300 \mathrm{~cm}^{-1}$ is observed. This broad band could correspond to the emission peak of the DL680 complex which is expected to be enhanced in the presence of the europium metal. Metal enhanced fluorescence is thus seen to occur here.

\section{Transmission electron microscopy imaging}

The Transmission Electron Microscopy (TEM) imaging studies

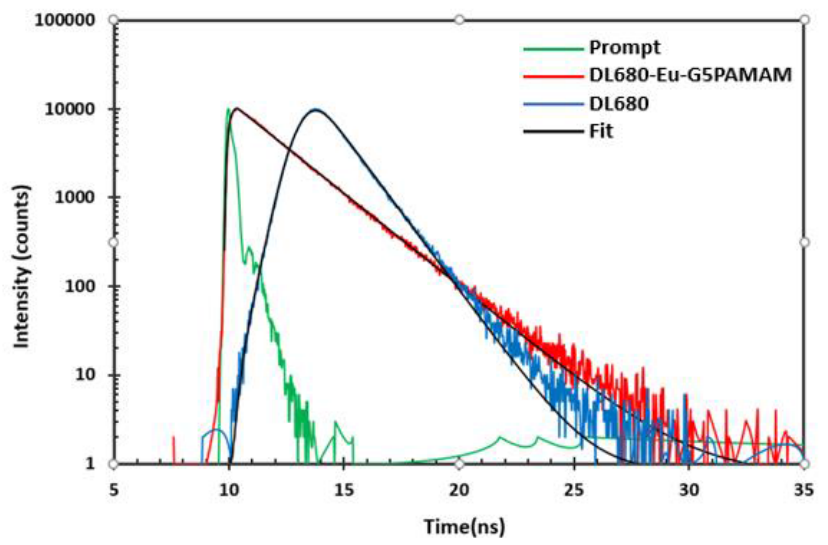

Figure 5: Fluorescence Lifetime measurement of DL680 and DL680-EuG5PAMAM.

\begin{tabular}{|c|c|c|}
\hline Sample & Lifetime $\left.\mathbf{(}_{\mathbf{1}}\right)(\mathbf{n s})$ & Standard Deviation $(\boldsymbol{\sigma})$ \\
\hline DL680-Eu-G5PAMAM & 2.11 & 0.0027 \\
\hline DL680 & 1.25 & 0.0025 \\
\hline
\end{tabular}

Table 2: Fluorescence lifetime measurement of DL680 and DL680-Eu-G5PAMAM. 
Citation: Ghann W, Kang H, Uddin J, Gonawala SJ, Mahatabuddin S, et al. (2018) Dendrimer-based Nanoparticle for Dye Sensitized Solar Cells with Improved Efficiency. J Nanomed Nanotechnol 9: 496. doi: 10.4172/2157-7439.1000496

were carried to analyze the sizes of DL680-Eu-G5PAMAM nanoparticles and their interaction with titanium dioxide nanoparticles. Figure 7 shows the High-resolution TEM images of DL680-Eu-G5PAMAM and the corresponding histogram. The average size of the DL680Eu-G5PAMAM nanoparticles was determined to be $4.89 \mathrm{~nm}$ with a standard deviation of $0.89 \mathrm{~nm}$. Just a cursory look at the image as illustrated in Figure 7 shows the DL680-Eu-G5PAMAM nanoparticles

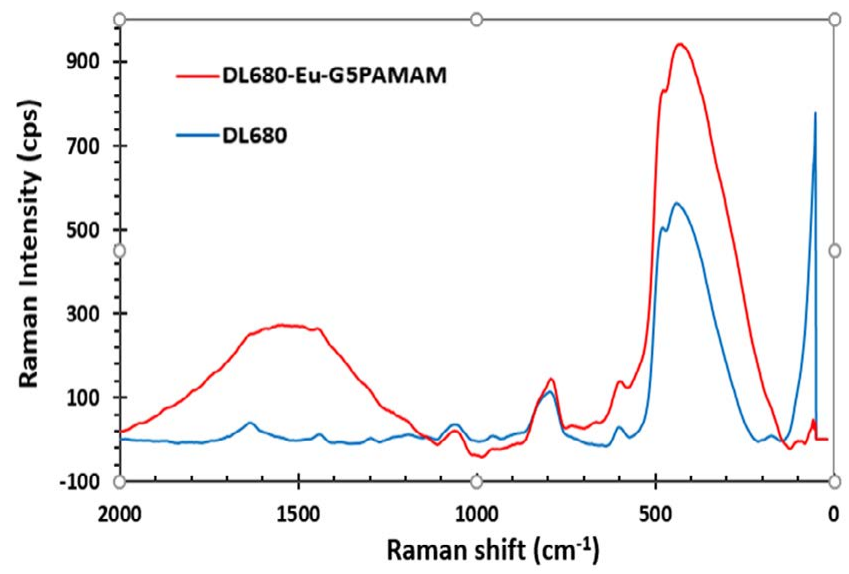

Figure 6: Raman Spectra of DL680 and DL680-Eu-G5PAMAM. to be uniformly distributed. Figure 8 displays the High-resolution TEM images of DL680-Eu-G5PAMAM (a) DL680-Eu-G5PAMAM/ $\mathrm{TiO}_{2}$ sample (b), bare $\mathrm{TiO}_{2}$ nanoparticles (c), and a FTT image of the $\mathrm{TiO}_{2}$ (d). The images of DL680-Eu-G5PAMAM with $\mathrm{TiO}_{2}$ suggest considerable interaction between the dye and the $\mathrm{TiO}_{2}$ nanoparticles.

\section{Energy dispersive $\mathrm{X}$-ray spectrometry studies}

The elemental composition of the dye sensitized titanium dioxide film was confirmed by Energy Dispersive X-Ray spectrometry (EDS) studies. Figure 9a shows the EDS spectra of europium conjugated dye whereas Figure 9b shows the EDS of dye sensitized titanium dioxide film. The elements carbon, oxygen, copper and europium are displayed in the EDS spectra of the DL680-Eu-G5PAMAM. The copper originates from the grid used in the measurement whereas Eu peaks confirms the presence of the dye

\section{Current-voltage characteristics of DL680 and DL680-Eu- G5PAMAM DSSC}

The studies on the photovoltaic performance of DL680 and DL680Eu-G5PAMAM DSSC under simulated solar irradiation of AM $1.5 \mathrm{G}$ were undertaken and the results are displayed in Figure 10 with the corresponding current-voltage characteristics parameters presented in Table 1. In the case of DL680-Eu-G5PAMAM DSSC, 0.32\% solar-toelectric conversion efficiency was realized with a short circuit current

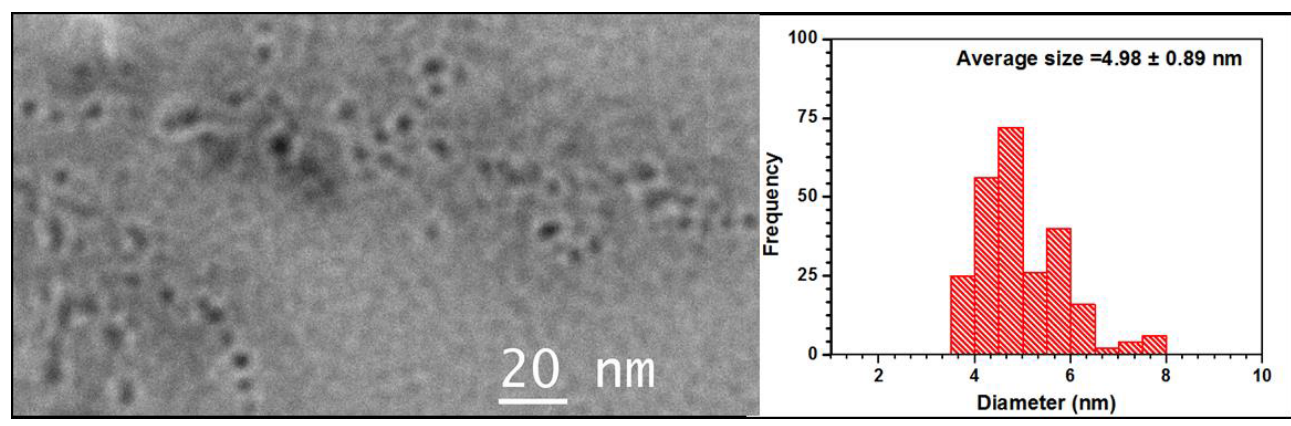

Figure 7: High-resolution TEM images of DL680-Eu-G5PAMAM and the corresponding histogram showing the size of the dye to be $4.98 \mathrm{~nm}$ with a standard deviation of 0.89 .

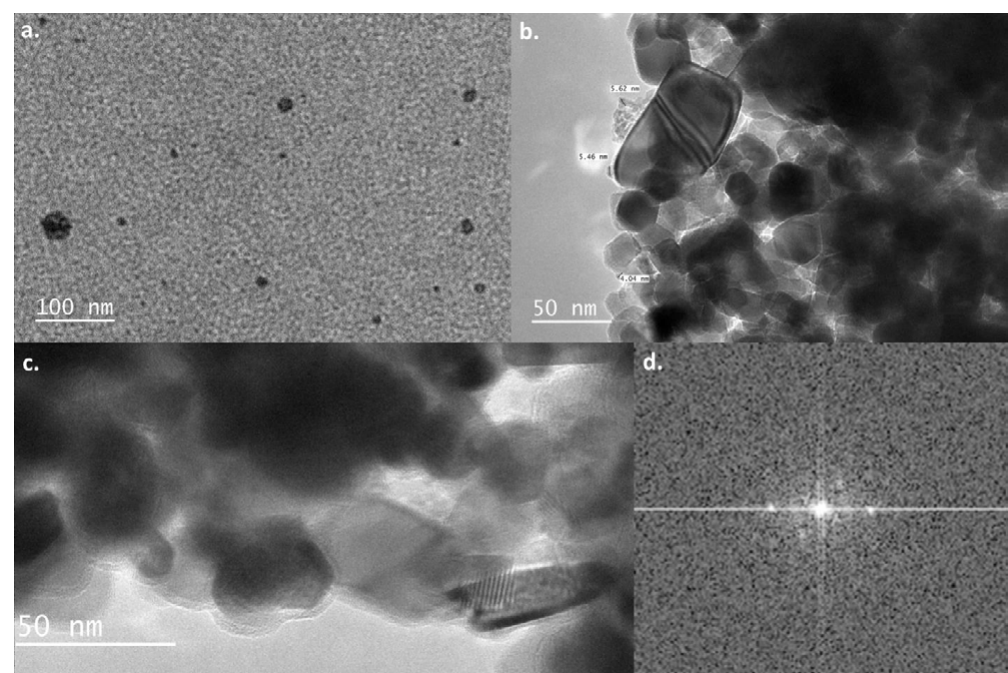

Figure 8: High-resolution TEM images of a $\mathrm{TiO}_{2}$ and a DL680-Eu-G5PAMAM /TiO ${ }_{2}$ samples and a FTT image of the TiO ${ }_{2}$ (a) high resolution TEM images of DL680-Eu-G5PAMAM dye, (b) TEM of DL680-Eu-G5PAMAM dye/TiO ${ }_{2}$, (c) bare $\mathrm{TiO}_{2}$ nanoparticles, (d) FTT Image. 
Citation: Ghann W, Kang H, Uddin J, Gonawala SJ, Mahatabuddin S, et al. (2018) Dendrimer-based Nanoparticle for Dye Sensitized Solar Cells with Improved Efficiency. J Nanomed Nanotechnol 9: 496. doi: 10.4172/2157-7439.1000496

Page 5 of 6
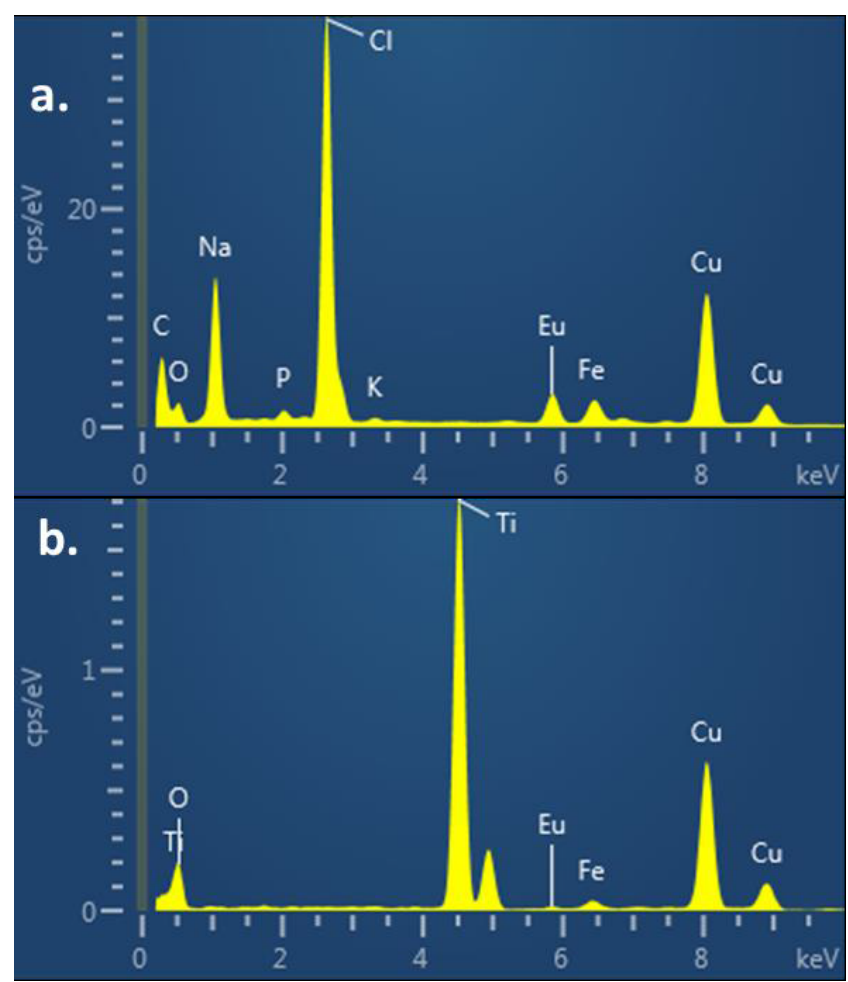

Figure 9: EDS Analysis of DL680-Eu-G5PAMAM without $\mathrm{TiO}_{2}$ nanoparticles (a) and with $\mathrm{TiO}_{2}$ nanoparticles (b).

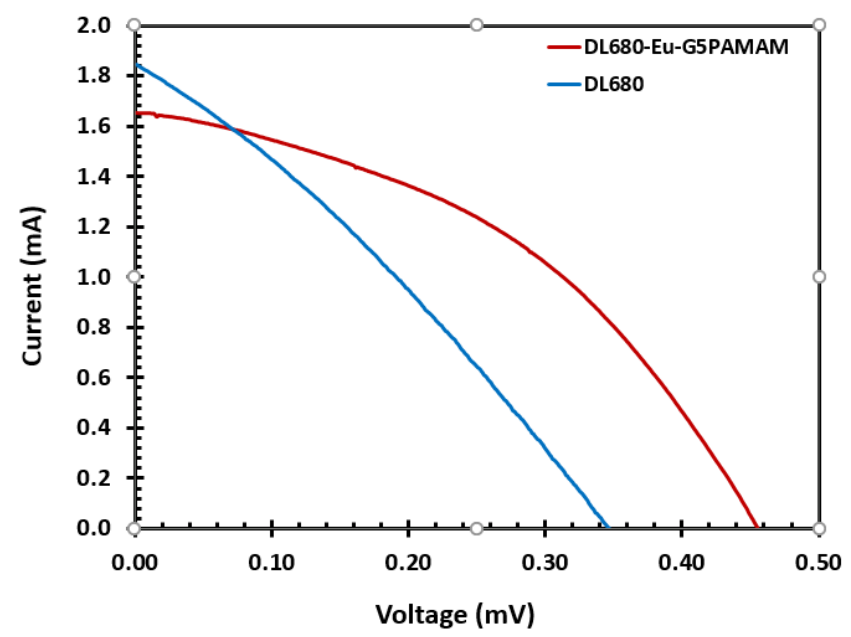

Figure 10: Photocurrent-voltage characteristics of DL680 and DL680-EuG5PAMAM dye sensitized solar cell measured under illumination of $100 \mathrm{~mW} /$ $\mathrm{cm}^{2}$ (1.5 AM).

of $1.66 \mathrm{~mA} / \mathrm{cm}^{2}$, open circuit voltage of $0.46 \mathrm{~V}$ and a fill factor of 0.42 . The efficiency of the DL680 on the other hand was $0.19 \%$ which is lower than that of DL680-Eu-G5PAMAM DSSC indicating that the inclusion of europium metal improved the efficiency of the resulting device. The improvement of the efficiency could be due to the presence of the europium that enhance the propensity of dye to absorb sunlight

\section{Electrochemical impedance spectroscopy}

Electrochemical impedance spectroscopy (EIS) is one of the vital tools employed to elucidate the charge transfer and transport processes in dye-sensitized solar cell (DSSC) devices [29-32]. EIS measurements were carried out to study the interfacial charge transfer occurring within the assembled DL680 and DL680-Eu-G5PAMAM DSSC. The results of this study are presented in the form of a Nyquist plot (Figure 11) and a Bode plot (Figure 12). The measurements were undertaken in the frequency range of $0.01 \mathrm{~Hz}$ to $100 \mathrm{KHz}$. The Nyquist plot shows two semi-circles with a semi-circle at the higher frequency demonstrating the electron transfer processes between the dye sensitized photoanode and the electrolyte interface. In addition, there is a little bit of difference at the intercept of the Nyquist plots of the fabricated DL680 and DL680Eu-G5PAMAM DSSCs for the $Z^{\prime}$-axis, at the high frequency end. This intercept point represents the series resistance, Rs, of the cells, arising from the FTO substrates and the external circuit wires.

Although there is a significant difference in the current-voltage characteristics of the solar cells, there are minimal differences in the electrochemical impedance spectroscopy data in terms of the resistance to the flow of charge and recombination losses as displayed in Nyquist and Bode plots.

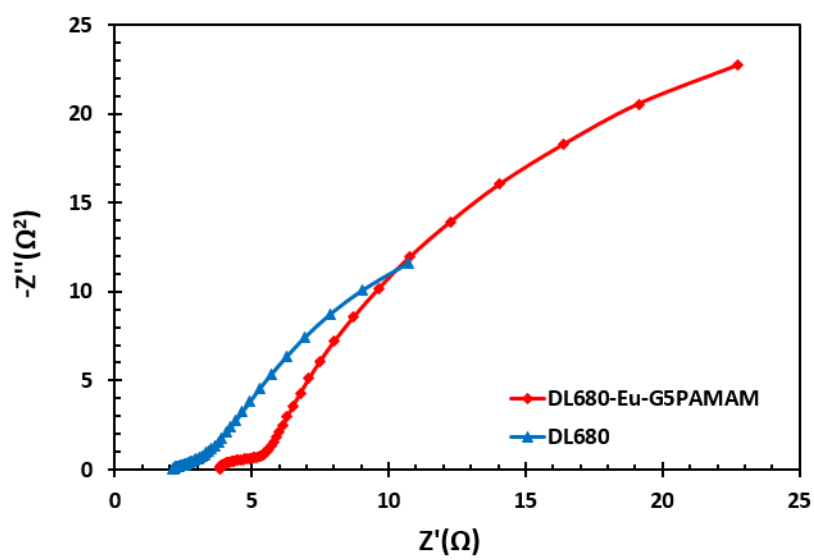

Figure 11: Nyquist plots for the fabricated DL680 and DL680-Eu-G5PAMAM dye sensitized solar cells showing differences in the resistances to charge transfer.

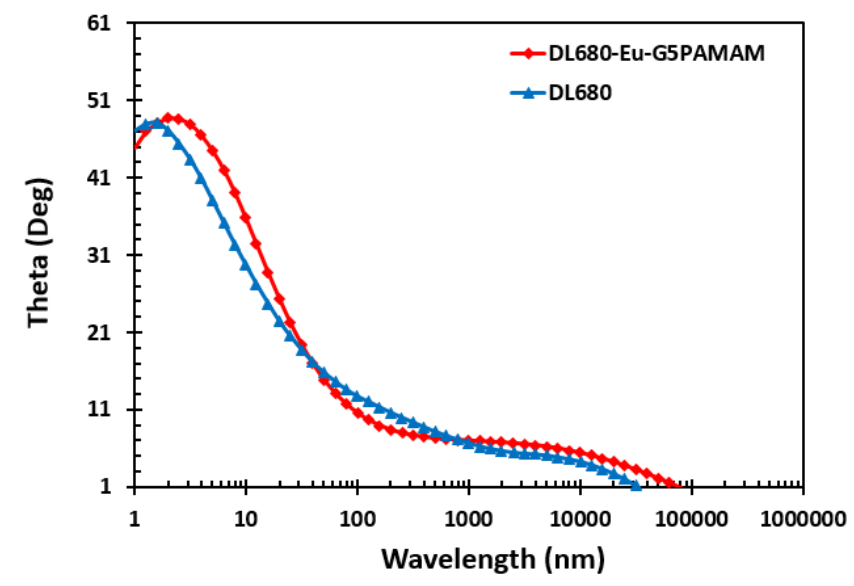

Figure 12: Bode plots for the fabricated DL680 and DL680-Eu-G5PAMAM dye sensitized solar cells. 
Citation: Ghann W, Kang H, Uddin J, Gonawala SJ, Mahatabuddin S, et al. (2018) Dendrimer-based Nanoparticle for Dye Sensitized Solar Cells with Improved Efficiency. J Nanomed Nanotechnol 9: 496. doi: 10.4172/2157-7439.1000496

Page 6 of 6

\section{Conclusion}

In conclusion, dye sensitized solar cells were fabricated with europium conjugated dendritic DL680 dye, 680-Eu-G5PAMAM, to study the effect of europium on the absorption characteristics of DL680 dye. The sensitizing dyes were first characterized using Absorption Spectroscopy, Emission Spectroscopy and Fluorescence lifetime, Fourier Transform Infrared measurements. They were also characterized using the Transmission electron microscope to obtain images and the respective sizes of the dye particles. The photovoltages characteristics of their respective dye sensitized solar cells were compared. The solar-to-electric conversion efficiency of DL680-EuG5PAMAM DSSC was $0.32 \%$ with a short circuit current of $1.66 \mathrm{~mA} /$ $\mathrm{cm}^{2}$, open circuit voltage of $0.46 \mathrm{~V}$ and a fill factor of 0.42 while solarto-electric conversion efficiency of DL680 was $0.19 \%$ with a short circuit current of $1.84 \mathrm{~mA} / \mathrm{cm}^{2}$, open circuit voltage of $0.35 \mathrm{~V}$ and a fill factor of 0.30 . The enhancement of the efficiency is suggested to be due to the presence of the europium in the dendritic dye.

\section{Acknowledgement}

The work was financially supported by the University of Maryland System Wilson E. Elkins Professorship, Constellation, an Exelon Company, E2-Energy to Educate grant program (163893), and Dept. of Education, SAFRA Title III Grant. The authors also acknowledge research support from the National Institutes of Health (NIH) grant RO1CA206190 to MMA. The authors are also grateful to the Institution of Advancement, Coppin State University, for administrative help. The content is exclusively the responsibility of the authors and does not necessarily represent the official views of the funding agencies.

\section{References}

1. Ye M, Wen X, Wang M, locozzia J, Zhang N, et al. (2015) Recent advances in dye-sensitized solar cells: from photoanodes, sensitizers and electrolytes to counter electrodes. Mater Today 18: 155-162.

2. Wei D (2010) Dye Sensitized Solar Cells. Int J Mol Sci 11: 1103-1113.

3. Ghann W, Kang H, Sheikh T, Yadav S, Chavez-Gil T, et al. (2017) Fabrication, Optimization and Characterization of Natural Dye Sensitized Solar. Cell Sci Rep 7: 41470

4. Mathew S, Yella A, Gao P, Humphry-Baker R, Curchod BFE, et al. (2014) DyeSensitized Solar Cells with $13 \%$ Efficiency Achieved through the Molecular Engineering of Porphyrin Sensitizers. Nat Chem 6: 242-247.

5. O'Regan B, Gratzel MA (1991) low-cost, high-efficiency solar cell based on dye-sensitized colloidal $\mathrm{TiO}_{2}$ films. Nature 353: 737-740.

6. Grätzel M (2009) Recent Advances in Sensitized Mesoscopic Solar Cells. Acc Chem Res 42: 1788- 1798.

7. Hagfeldt A, Boschloo G, Sun L, Kloo L, Pettersson H (2010) Dye-Sensitized Solar Cells. Chem Rev 110: 6595-6563.

8. Zhang Q, Park K, Xi J, Myers D, Cao G (2011) Recent progress in dyesensitized solar cells using nanocrystallite aggregates. Adv Energy Mater 1: 988-1001.

9. Yun S, Hagfeldt A, Ma T (2014) Pt-free counter electrode for dye-sensitized solar cells with high efficiency. Adv Mater 26: 6210-6237.

10. Lim SP, Pandikumar A, Lim HN, Ramaraj R, Huang NM, et al. (2015) Boosting Photovoltaic Performance of Dye-Sensitized Solar Cells Using Silver Nanoparticle-Decorated N, S-co-doped-TiO 2 Photoanode. Sci Rep 5: 11922.

11. Wei, W, Wang H, Hu YH (2014) A review on PEDOT-based counter electrodes for dye-sensitized solar cells. Int J Energy Res 38: 1099-1111.
12. Tian H, Sun L (2011) lodine-Free Redox Couples for Dye-Sensitized Solar Cells. J Mater Chem 21: 10592-10601.

13. Ondersma JW, Hamann TW (2013) Recombination and redox couples in dyesensitized solar cells. Coord Chem Rev 257: 1533-1543.

14. Kakiage K, Aoyama Y, Yano T, Oya K, Fujisawa J, et al. (2015) Highly-Efficient Dye-Sensitized Solar Cells with Collaborative Sensitization by Silyl-Anchor and Carboxy-Anchor Dyes. Chem Commun 51: 15894-71589.

15. Klfout $\mathrm{H}$, Stewart A, Elkhalifa M, He H (2017) BODIPYs for Dye-Sensitized Solar Cells, ACS Applied Materials \& Interfaces 9: 39873-39889.

16. Li LL, Diau EW (2013) Porphyrin-Sensitized Solar Cells. Chem Soc Rev 42 291-304.

17. Higashino T. Imahori H (2015) Porphyrins as Excellent Dyes for Dye-Sensitized Solar Cells: Recent Developments and Insights. Dalton Trans 44: 448-463.

18. Ali MM, Bhuiyan MP, Janic B, Varma NR, Mikkelsen T, et al. (2012) A nanosized PARACEST-fluorescence imaging contrast agent facilitates \& validates in vivo CEST MRI detection of glioma. Nanomedicine (Lond) 7: 1827-1837.

19. Ishii A, Hasegawa M (2015) An Interfacial europium Complex on $\mathrm{SiO}_{2}$ Nanoparticles: Reduction-Induced Blue Emission System. Sci Rep 5: 11714.

20. Janic B, Bhuiyan MP, Ewing JR, Ali MM (2016) pH-Dependent Cellular Internalization of Paramagnetic Nanoparticle. ACS Sens 26: 975-978.

21. Ghann W, Kang H, Emerson E, Oh J, Chavez-Gil T, et al. (2017) Photophysical properties of near-IR cyanine dyes and their application as photosensitizers in dye sensitized solar cells. Inorganica Chimica Acta 467: 123-131.

22. Ghann W, Chavez-Gil T, Goede Cl, Kang H, Khan S, et al. (2017) Photophysical, Electrochemical and Photovoltaic Properties of Porphyrin-Based Dye Sensitized Solar Cell. Advances in Materials Physics and Chemistry 7: 148-172.

23. Ghann W, Sobhi H, Kang H, Chavez-Gil T, Nesbitt F, et al. (2017) Synthesis and Characterization of Free and Copper (II) Complex of N, N'-Bis(Salicylidene) Ethylenediamine for Application in Dye Sensitized Solar Cells. Journal of Materials Science and Chemical Engineering 5: 46-66.

24. Li Y, He H, Lu W, Jia X (2017) A poly(amidoamine) dendrimer-based drug carrier for delivering DOX to gliomas cells. RSC Adv 7: 15475-15481.

25. Chandrasekar D, Sistla R, Ahmad FJ, Khar RK, Diwan P (2007) The development of folate-PAMAM dendrimer conjugates for targeted delivery of anti-arthritic drugs and their pharmacokinetics and biodistribution in arthritic rats. Biomaterials 28: 504-512.

26. Matsumoto K (2011) Time-Resolved Luminescence Microscopy and Microarray Using europium Chelate Labels. In Microscopy: Science, Technology, Applications and Education.

27. Lahtinen S. Wang Q Soukka T (2016) Long-Lifetime Luminescent europium (III) Complex as an Acceptor in an Upconversion Resonance Energy Transfer Based Homogeneous Assay. Analytical Chemistry 88: 653-658.

28. Li T, Shang W, Zhang F, Mao L, Tang C, et al. (2011) Luminescent Properties of europium Complexes with Different Long Chains in Langmuir-Blodgett (LB) Films. Engineering 3: 301-311.

29. Sarker S, Ahammad AJS, Seo HW, Kim DM (2014) Electrochemical Impedance Spectra of Dye-Sensitized Solar Cells: Fundamentals and Spreadsheet Calculation. International Journal of Photoenergy.

30. Adachi M, Sakamoto M, Jiu J, Ogata Y, Isoda S (2006) Determination of parameters of electron transport in dye-sensitized solar cells using electrochemical impedance spectroscopy. J Phys Chem B 110: 13872-13880.

31. Bisquert J, Fabregat-Santiago $F$ (2010) Impedance spectroscopy: a general introduction and application to dye-sensitized solar cells. Taylor \& Francis, Boca Raton, Fla, USA.

32. Bisquert J, Fabregat-Santiago F, Mora-Sero I, Garcia-Belmonte G, Giménez S (2009) Electron lifetime in dye-sensitized solar cells: theory and interpretation of measurements. J Phys Chem C 113: 17278-17290. 